\title{
Dental changes evaluated with a 3D computer-assisted model analysis after long-term tongue retaining device wear in OSA patients
}

\author{
Hui Chen • Alan A. Lowe • Arthur M. Strauss • \\ Fernanda Riberiro de Almeida $\cdot$ Hiroshi Ueda • \\ John A. Fleetham $\cdot$ Bangkang Wang
}

Published online: 11 November 2008

(C) Springer-Verlag 2008

\section{Erratum to: Sleep Breath (2008) 12:169-178}

DOI 10.1007/s11325-007-0141-y

Unfortunately, the figure legends were given incorrectly in our article. The figure legends should be as follows:

Fig. 2 legend is in the correct order but actually should be beside the photos of models for Case 1 which appear in the manuscript opposite the Fig. 4 legend

Fig. 3 legend is in the correct order but actually should be beside the computer prints of 5 cases which appear in the manuscript opposite the Fig. 2 legend

Fig. 4 legend is in the correct order but actually should be beside the graphs which appear in the manuscript opposite the Fig. 3 legend

The online version of the original article can be found at http://dx.doi. org/10.1007/s11325-007-0141-y.

H. Chen $\cdot$ B. Wang

Department of Orthodontics, Faculty of Stomatology,

The University of Medical Sciences,

Beijing, People's Republic of China

H. Chen $\cdot$ A. A. Lowe $\cdot$ H. Ueda

Division of Orthodontics, Department of Oral Health Sciences, Faculty of Dentistry, The University of British Columbia,

Vancouver, Canada

\section{A. M. Strauss}

DDS, Private Dental Clinic, Specialist in Snoring \& Sleep Apnea,

311 Park Avenue Falls Church, VA 22046, USA
F. R. de Almeida

Department of Oral Biological and Medical Sciences,

Faculty of Dentistry, The University of British Columbia,

Vancouver, Canada

\section{J. A. Fleetham}

Division of Respiratory Medicine, Department of Medicine,

The University of British Columbia,

Vancouver, Canada

Present address:

H. Chen $(\triangle)$

2199 Wesbrook Mall,

Vancouver, BC V6T 1Z3, Canada

e-mail: huichen@interchange.ubc.ca 